Int.J. Hum. Soc. Dev. Res.

ISSN(P):2521-1439; ISSN(E):2523-4331

Volume 5, Number 2, 2021. 7-19

DOI: $10.30546 / 2523-4331.2021 .5 .2 .7$

\title{
INNOVATION IN HEALTH MANAGEMENT AND SOCIAL CARE
}

\author{
Asena Tugba EVREN SUBASI
}

Near East University, North Cyprus

\section{Gokhan SUBASI}

Cyprus International University

\section{ABSTRACT}

Today, more challenging competition environment and dynamic conditions caused by globalization have led to the desire to provide competitive advantage and to be sustainable in health sector as well as all sectors. This motivates the health organizations to establish a new innovative understanding and continuous development processes. The only factor leading to this situation are not competitive conditions, also the availability of human and human life at the center of the sector is another factor leading to this situation. Health expenses, which occupy a highly significant place in the world, have reached a leading level in all sectors in the research and innovation field together with the development of new technologies and administrative methods. This research aims to reveal the understanding and requirements of innovation in health management.

\section{C2021.All rights reserved.}

\section{ARTICLE HISTORY}

Received: 12/12/2020

Accepted: 09/05/2021

Published online: 01/10/2021

\section{KEYWORDS}

Sustainable, health sector, social care, new technologies, human life 


\section{Introduction}

The health sector, vision of which changes each passing day, has started to deal with innovative products and processes along with developing technologies. Early diagnosis and treatment facilities have been developed, which will reduce future costs and provide convenience and high performance in long term in health services. In the context of public policy, health systems primarily aim to increase the accessibility to health organizations and health services.

According to the Oslo Manual (2005); treatment of diseases, which cannot be diagnosed early, delay and it can result in higher costs than usual conditions. Innovation in health services contributes to the development of sustainable solutions together with increased productivity.

The health sector, which is of a great importance, especially one of the priority service sectors of developed economies. Innovative understanding in health services also contributes to the development of society and to economic growth. According to Tezcan (2016), approximately 7-7.5\% of GDP of the developed economies consists of services or products developed by health sector. The rate of the health sector in total employment also shows an increase up to $10 \%$ in the same countries. Approximately $16 \%$ of GDP is expected to be composed of health expenses by 2020 . With the rapidly increasing health expenditures all over the world, the health sector becomes the most important consumer of innovative technologies in the world.

When the trends of growth and development in the health sector are taken into the consideration, it would not be wrong to say that making innovation on behalf of health institutions now significantly becomes obligatory. Especially when period of time after 2000 is examined, it is seen that technological developments primarily affect the health sector (Tezcan, 2016).

According to Cresswell and Sheikh (2016); the main factor, which opens the way in order for healthcare institutions to be sustainability and to gain advantage under the strong conditions of competition by means of differing from rival organizations, is their 
innovation approach. Miller and French (2016) have shown that health organizations are obliged to develop a variety of strategies by means of integrating with technology and innovation to respond to social and individual expectations as a result of dynamic competition conditions and market pressure.

Since innovation understanding in health sector also necessitates an increase in quality along with competitiveness and sustainability as mentioned above, it forms a basis to struggle with synchronously increasing costs. Health organizations comply with various standards and take innovative steps in order to offer quality service. According to Omachonu and Einspruch (2010), innovation understanding focuses primarily on the provision of cost-quality balance in health services. Innovation in this direction is financially one of the most important factors of the increase in productivity in the health sector.

\section{The importance of human resources management in health care}

Health services are tightly tightened with health workers offering these services to the health service receiver. Health professionals are also effective in terms of quality perception of health service receivers as effective in increasing efficiency and efficient studies from these services and efficiency.

The main objective of firms and technical investments made from the technical point of view is to influence the performance in a positive way by providing a level of certain efficiency and activity. Increasing the efficiency and effectiveness, the exceeding the current performance level is significantly qualified, skilled and sufficient level of knowledge with the adaptation of the team in teamwork. A sensitive and dynamic working structure of employees with different areas of expertise in health services should be rationalized with teams to use quantitative and scientific methods by experts. Health services are the services offered as a team. There are many different occupational groups in health services and the best presentation of health services should work in accordance with these occupational groups (Kavuncubasi and Yildirim, 2012: 353). Full this moment is the human resources management. 
On the other hand, there is a binary management structure in health businesses. "Clinical Administrators" and "Service / Resource Managers", from different expertise and educational areas, are fulfilling quite different tasks and responsibilities from each other to ensure the enterals of the business. Clinical managers and departments perform health care production, the mission and the main task of health businesses. Other burning service / resource managers support and manage the structure that performs health care production. In terms of command in terms of command, the disruptions in these works are causing serious disruptions and problems in areas where the major service production is made. Nahli vd. (2015: 700) states that the most effective organization of human resources in the creation of the working model for more efficient assessment of density in hospital services.

For success in health services that directly affect human life; It is a value that creates value and must feel that you are accepted within the business. The fact that the human resource feels valuable is the basic requirements of using the stored potential, abilities, health institutions and patients in the direction to create value.

In order to avoid damage to medical errors, human resources management has a significant impact. Suitable for principles and standards determined in recruitment processes, issues such as the presence of a strong organization culture, employee motivation and satisfaction are important human resources tools at the point of improving the performance of the health system and prevention errors. Porter (2014: 7) Emphasizes health care professionals whose health care services needed health professionals who are devoted to this service.

The importance of health care employees, the importance of health care employees of the production of health services, is one of the building blocks of human resources of human resources management. (Bertone and Witter (2015: 57) and Buchan (2004: 5))

Health enterprises are under the influence of modern developments, and are transmitted to the change and transformation and develop strategies that adapt to these changes and transformations, and there are always needs and expectations of service users / patients with internal and external stakeholders. The presence of service recipients that do not have knowledge and education in a professional way of evaluation 
of health services, evaluate the quality and preferred service to the perception of quality and preferred service.

It is extremely important to provide human resources management and practices designed to meet the expectations of the personnel working in health institutions (Korkmazyurek, 2019). The health personnel, which are the main manufacturer of health care and health care, will be able to provide efficient and effective service in an institution where the expectations are met and feel happy. Therefore, it is necessary to determine and implement in accordance with the employee expectations and desires of Human Resources Management applications.

Active Human Resources Management is an important issue for the success and continuity of health systems. United Nations Millennium Development Goals (Millennium Development Goals) to the health indicators determined within the scope of Millennium Development (reduction of baby death rate, improving maternal health, fighting with HIV / AIDS, HIV Human resources have an important place. Anand and Barnighausen (2004: 1606) emphasized that the intensity of human resources is important for the health system; The mother has found that the mortality rate was the relationship between the infant death rate and human resource density with five death rates. They also stated that investments to the human resources have to be taken into consideration that the countries achieve thousand years of developmental targets of countries. Correia vd. (2015: 1603) states that health policies should be developed for more efficient use of the workforce in the efficiency of health services.

Human Resources Policy in an open, understandable and qualified manner has the performance of the performance of the country health systems. Effective policies; The regulation of the health human resource density (medical and administrative human resources), the appropriate and balanced distribution of the human resource provides positive gains at the points of the performance of the human resources. (Bossert vd., 2007)

Kuhlmann and Larsen (2015: 1640), people who work in hospital services are difficult to manage this complexity that occurs in many different occupational groups and emphasizes the importance of strategic human resources management, but the 
health services are needed to be more sustainable for managerial innovations to be sustainable for human resources management.

In the health institutions that offer services with advanced technology, significant changes and transformations in the human power are needed. The human power needed is expected to be compatible with new technologies.

Health institutions are viewed in terms of human power; It can be defined as strenuous and labor intensively that requires both bodily and mentally significant attention. Considering all these situations, even the smallest mistakes to serve quickly and correctly will be able to result in great harms even with the termination of human life.

The innumerable technological applications used in health systems are mandatory to change human resources management in this field.

As with all the service sectors, in the health sector, in the health sector, the human resources management that determines the right strategies to determine the correct strategies by directing the Human Resources Management of Human Resources Management of Human Resources Management and the minimization of errors in the diagnosis, diagnostic and treatment chain with quick diagnosis, accurate diagnosis and on-site therapies. (Counts and High, 2018, p. 11) The rapid diagnosis, accurate diagnosis and most accurate treatment method is aimed at increasing efficiency and costs by minimizing medical errors. (Kumari et al., 2018, p.13).

Businesses that manage human resources in a manner with other resources to fulfill the objectives of the business as most efficient and effective in the harmony to increase the competitive superiority.

In order to be preferred in health business, it is important for sustainability, competitiveness, cost advantage, patient satisfaction, to be able to process the basic ability of focus on the basic ability to process effectively and efficiently. When considered for health institutions, the human resource is significantly determinant of the scope and presentation of the service. 
In order to establish the quality and performance of health institutions in determining the quality and performance of the qualified health personnel in determining the quality of health personnel, it is necessary to take these elements to improve their organizational commitment by improving its organizational commitment by improving their organizational commitment to create an organizational level of organizational commitment within the organization. Meeting the basic physiological requests of employees, responding to the feeling of belonging on the basis of an institution, the fulfillment of the need to be valued, respecting and appreciated, etc. they are in expectations. The unit to respond to these expectations is human resources management. As a matter of fact, efficiency of health services, human resource is important in the effective, efficient and quality manner, but the nature and management of the human resources have gained importance for health institutions.

The rapid and destructive technological change has led to the globalization of both production and consumption "intensive competition". The challenges of the competitive advantage is temporary, and the global pandemia requires continuous renewal of new and distinguished starategors for organizational survival and success (Ammad et al., 2020, p. 1).

The best manager of human resources, which enable human resources in the center of the human resources in the center of the organization, by preparing the work environments they will use the work environments towards the employees and using the correct use of human power, and the human power is one of the most important resources, is one of the most important resources, is one of the most important resources, is one of the most important sources. It can ensure that the organization can achieve a sustainable competitive force by using the use of the varying and developing conditions.

Health institutions implement data and innovations, which are obtained as a result of following of current developments, by means of integrating them into their own processes. This situation also leads to reduce the costs. In addition to this, quality of health services increases and patient satisfaction is increasingly provided. According to Gaynor and Town (2011); along with advances in information and communication 
technologies, easy access to information increases the quality expectation for patients and a more selective and conscious mass emerges. For this reason, when individuals become sick, they prefer more quality and more comfortable health organizations instead of the closest health organization. This creates an important competitive environment for health institutions. According to Barrett et al. (2015), the changing expectations of patients and their relatives have led to the diversification of the services provided by health organizations, both in terms of content and scope. For example, there has been an increase in demand for health services such as home care services with increased life expectancy and health organizations have begun to compete with each other for this and similar applications.

Health enterprises take steps to increase their productivity and effectiveness in order to meet the changing and growing demands. The adoption of innovation in sectorial sense and its acceptance as a philosophy in health organizations have importance both in terms of the increasing in quality and being reason for preference (Fong and Harris, 2015: 438).

Health organizations and the health sector experience a new structuring process both in administrative and medical sense. Today's practices and advances in medical technology also present significant opportunities for redesigning and restructuring the health services (Özgener and Küçük, 2008: 345).Early diagnosis and improvement of success rates in treatments and reflection of the innovations in information technologies to health organizationscan be seen as the basic dynamics of revisions in the health sector (http://www.saglik.gov.tr/).

In a study in which they applied factor analysis and hypothesis tests in 34 hospitals in Portugal in 2017; They concluded that service and process innovations affect operational performance.( Moreira M.R.A., Gherman, M. \& Sousa, P.S.A. 2017)

In the context of innovation and restructuring in health organizations, reduction of bureaucracy and recruitment suitable for principle of merit in health services become an important necessity (Ginn et al., 2006: 111).However, it is also seen that the managements in the health organizations have adopted organizational philosophies that focus on innovation in the field of patient care. According to Ozgener and Kuçuk 
(2008), both using more efficient the available resources and providing the sustainability of existence of innovative services will be possible by means of integrating modern management techniques and medical innovations into the system to respond to changing demands.

In southern Brazil, four health plan operators and two internationally accredited hospitals were analyzed using a framework based on managed care (MC) and innovation management criteria. In the answers given to the research questionnaire, it was observed that hospitals were higher in Health Plan Operators, and the highest compliance rate for both health plan operators and hospitals was found in the management criteria of medical services. The managed care and innovation criteria state that a patient-centered approach can benefit by reducing the costs of services provided, demonstrating quality chain and innovation of the value chain and innovation in healthcare management. (Marciano, M. A., Vaccaro, G. L. R., Roris Rodriguez Scavarda do Carmo, A. J., Fabiano de Lima Nunes \& Nodari C. H. 2020)

Productivity is especially one of the priority issues in health management as mentioned above. Adoption of new methods and techniques is of a great importance to achieve the productivity criteria. Similarly, Wu and Hsieh (2011)state that it is an obligation for health organizations to exhibit an innovative approach both in terms of administrative and medical in order to adopt the innovation philosophy in health management.

Since the basic consumer of innovation in health institutions will be individual and society, human takes place in the center of health service. In this respect, the main goal of innovation in health management is to create a healthy population. Innovative approaches cause health institutions and the countries, in which health institutions are located, to increase their competitive power. Early diagnosis and treatment procedures develop together with innovation understanding and extensions of innovation and as a result of the researches made in accordance with these conditions, export opportunities arise. According to TÜSİAD report belonging to year 2016 written by Tezcan (2016), innovative understanding and $\mathrm{R} \& \mathrm{D}$ capacity in the health sector also constitute an 
example for other sectors together with technological opportunities and accumulation of knowledge.

It can be said that public institutions occupy an extensive place in health sector, where privatizations and merger of companies are seen in a widespread manner, and especially in Turkey. In this respect, it will not be wrong to say when innovation is mentioned that innovation in the public sector will not be as fast as innovation in the private sector.

Competition in the health organizations affiliated to the public is much lower than that of the private sector and choice opportunity for people in public institutions is less than that of the private sector. Although various pressures on change and innovation are created, the public sector fails to be in the forefront of change as much as the private sector. For example, even if the applications carried out to reduce the costs lead to good results, the health organizations affiliated to the publican be late in decision making about these practices due to the bureaucracy compared to the private sector. According to Bessant and Maher (2009), this situation postpones or makes difficult the innovation movements in health organizations affiliated to the public.

In a study published in 2020, it was revealed that the social innovation dimension of innovation provides more transparent and sustainable services to local beneficiaries, organizing and advancing health programs.( Halpaap BM, Tucker JD, Mathanga D. et al. 2020)

In particular, managerial and medical developments emerging in the lastperiod determine the direction of the health sector. The arrival of the human genetics in the solution phase and development process in the pharmacy sector has made it possible to overcome chronic and very difficult diseases. When considered under health sector umbrella, it is known that industries, which are considerably open for innovative understanding, are biotechnology, pharmaceutical and medical device industries (Herzlinger, 2006: 58).A large part of the global funds are also used in the health sector. Especially medical innovation and researches need to very serious investments. However, in spite of investments, it should not be forgotten that innovations and developments will cause to significantly yield a financial profit in the long term. For 
example, it has been thought that a drug, which has been developed against a type of cancer and for which a great investment has been made, would cause to far less cost in the long term compared to treatments to heal cancer that should be carried out under normal conditions. This situation proves that the return on investments made in R \& D studies will be ensured (Deloitte, 2016: 94).

\section{Result}

Health organizations should continuously improve and develop themselves to ensure patient satisfaction and to be preferable along with challenging competition conditions, preventive health care services and new developments appearing in treatment stages. As a result of differentiation of social needs and expectations in due course, it is necessary for the health organizations to change and transform themselves and the services that they offer. The increase in income level and the development process in medical devices create a more qualified health service expectation for the individuals and every part of community with the effect of technology. The early diagnosis and increase in treatment methods, the availability of medical devices and all resources whenever necessary, the allocation of sufficient financial resources for research and development, the feedbacks receiving from patients and the integration of current scientific arguments into each unit of the organization are important results of the innovative approach in the health sector. In this context, with the placement of the innovation understanding in the health sector, quality understanding develops through both functional and managerial innovations.

\section{Disclosure statement}

No potential conflict of interest was reported by the authors.

\section{Contact Information}

E-mail: a.tugbaevrens@gmail.com 


\section{References and notes:}

Ahammad MF, Glaistera KW, Gomes E. Strategic Agility and Human Resource Management. Human Resource Management Review, 30; 2020.

Anand, S. and Bärnighausen, T. (2004). "Human Resources and Health Outcomes: CrossCountry Econometric Study", Articles, 364, 1603-1609

Barrett, M., Davidson, E., Prabhu, J., \& Vargo, S. L. (2015). Service innovation in the digital age: key contributions and future directions. MIS quarterly, 39(1), 135-154.

Bertone, M.P. and Witter, S. (2015). "An Exploration Of The Political Economy Dynamics Shaping Health Worker Incentives In Three Districts In Sierra Leone”, Social Science \& Medicine, 56-63.

Bessant, J., \& Maher, L. (2009). Developing radical service innovations in healthcare-the role of design methods. International Journal of Innovation Management, 13(04), 555-568.

Bossert, T. J., Bossert, T., Bärnighausen, T., Bowser, D., Gedik, G., Mitchell, A. (2007). Assessing Financing, Education, Management and Policy Context for Strategic Planning of Human Resources For Health. World Health Organization

Correia, T., Dussault, G. and Pontes, C. (2015). "The Impact Of The Financial Crisis On Human Resources Forhealth Policies In Three Southern-Europe Countries", Health Policy, 1600-1605.

Cresswell, K. M., \& Sheikh, A. (2016). Catalysing health information technology innovation in the National Health Service. Journal of the Royal Society of Medicine, 109(12), 439440 .

Deloitte. (2016). Global healtycare Outlook: Battling costs White improving care. London, Touche Tohmatsu.

En-Nahli, L., Allaoui, H. and Nouaouri, I. (2015). "A Multi-objective Modelling to Human Resource Assignment and Routing Problem for Home Health Care Services", IFAC Papers Online, 698-703.

Fong, H., \& Harris, E. (2015). Technology, innovation and health equity. Bulletin of the World Health Organization, 93(7), 438-438.

Gaynor, M., \& Town, R. J. (2011). Competition in health care markets. In Handbook of health economics (Vol. 2, pp. 499-637). Elsevier.

Ginn, G. O., Lee, R. P., \& Ellis, T. (2006). Community orientation, strategic flexibility, and financial performance in hospitals. Journal of healthcare Management, 51(2), 111.

Halpaap BM, Tucker JD, Mathanga D. et al. (2020): Social innovation in global health: sparking location action. The Lancet Global Health. May 2020 vol 8(5): e633-e634. DOI: https://doi.org/10.1016/S2214-109X(20)30070-X

Herzlinger, R. E. (2006). Why innovation in health care is so hard. Harvard business review, 84(5), 58.

Kavuncubasi S, Yildirim S, (2012). Hospital and Health Institutions Management, 3. Printing, Ankara: Political Bookstore

Korkmazyürek, Y. (2019). Human resources management in health institutions, Management of health institutions (Editors: Demirci, A. and Manavgat, G.), Gazi Bookstore, Ankara, P.102.

Kuhlmann, E. and Larsen, C. (2015). "Why We Need Multi-Level Health Workforce Governance: Casestudies From Nursing And Medicine In Germany", Health Policy, 119(12), 1636-1644.

Kumari A, Tanwar S, Tyagi S, Kumar N. Fog computing for Healthcare 4.0 environment: Opportunities and Challenges. Elsevier, Computers and Electrical Engineering. 72:1$13 ; 2018$.

Mahasneh, M. S. M., Alnahdi, S. A., Bani-Hani J. S. (2020): Innovation in Health Services alignment with the Competitive Advantage Achievement in Private Hospitals in Saudi

Int.J. Hum. Soc. Dev. Res.

Volume 5, № 2, 2021.7-19 
Arabia: Strategic Evidence. International Journal of Business and Social Science Vol. $11 \cdot$ No. 3 • March 2020 doi:10.30845/ijbss.v11n3p858)

Marciano, M. A., Vaccaro, Annibal José Roris Rodriguez Scavarda do Carmo, Nunes, F. L. \& Nodari C. H. (2020): Managed care and innovation in healthcare management: a Brazilian experience. International Journal of Healthcare Management Received 01 May 2018, Accepted 22 Jun 2020, Published online: 01 Jul 2020 https://doi.org/10.1080/20479700.2020.1788333

Miller, F. A., \& French, M. (2016). Organizing the entrepreneurial hospital: Hybridizing the logics of healthcare and innovation. Research Policy, 45(8), 1534-1544.

Moreira, M. R. A., Gherman M. \& Paulo S. A. Sousa. (2017): Does innovation influence the performance of healthcare organizations?, Innovation: Organization \& Management, Volume 19, 2017 - Issue 3, Pages 335-352

Omachonu, V. K., \& Einspruch, N. G. (2010). Innovation in healthcare delivery systems: a conceptual framework. The Innovation Journal: The Public Sector Innovation Journal, $15(1), 1-20$.

Oslo Kilavuzu. (2005). Principles for the collection and interpretation of innovation data. (Translated by.: TÜBİTAK). Third Edition, Ankara: TÜBITTAK Publications

Özgener, Ş., \& Küçük, F. (2008). Effect of modern management philosophy in the hospitals on productivity: An Application in Gevher Nesibe Hospital. Selçuk University Social Sciences Institute Magazine, (19), 341-358.

Porter, M. E. (2014). Value-Based Health Care Delivery, Harvard Business School, 1-28, http://www.hbs.edu/healthcare/Documents/2012\%2003\%2007\%20SUT\%20HCI\%20p resentation.pdf. (Erişim Tarihi: 9 Mart 2016).

Sayar M, Yüksel H. Industry 4.0 and Industry 4.0 Transformation in the Turkish Public Sector. Journal of Law and Economic Studies. Volume 10, Issue 2; 2018.

T.R. Ministry of Health Web Sitesi, http://www.saglik.gov.tr/

Tezcan, C. (2016). An Innovative Viewpointfor Health: Mobile Health, TÜSİAD-T/2016$03 / 575$.

Wu, I. L., \& Hsieh, P. J. (2011). Understanding hospital innovation enabled customer-perceived quality of structure, process, and outcome care. Total Quality Management, 22(2), 227-241. 